\title{
La Monarquía Hispánica defensora de la Inmaculada Concepción, a través de algunas estampas españolas del siglo XVII
}

\author{
Juan Isaac Calvo Portela \\ Departamento de Arte II (Arte Moderno) \\ Facultad de Geografía e Historia, Universidad Complutense de Madrid \\ uaniscporte16@hotmail.com
}

\section{RESUMEN}

En el siglo XVII la Monarquía Hispánica fue la gran defensora de la doctrina de la Inmaculada Concepción, y en varias ocasiones los monarcas trataron que el misterio se elevara a dogma de fe. Dicha actitud de los reyes va a tener su reflejo en las distintas manifestaciones artísticas, siendo una de las más interesantes las estampas que acompañaban a los muchos tratados que sobre la doctrina se editaron en España en esa centuria. Aquí estudiamos cuatro ejemplos de mediados de siglo, aunque se podrían haber puesto otros muchos e igual de interesantes.

Palabras clave: Estampa; Monarquía; Inmaculada Concepción; Defensa; Doctrina.

\section{The Spanish Monarchy defender of the Immaculate Conception, through some seventeenth-century spanish prints}

\begin{abstract}
In the $17^{\text {th }}$ century the Spanish monarchy was the great defender of the doctrine of the Immaculate Conception, and the kings repeatedly tried the mystery to be raised to dogma of faith. This attitude will be reflected in different artistic expressions, among which the prints that accompanied the many treatises on the doctrine that were published in Spain in this century are one of the most interesting exponents. Here we study four examples dating from the 1650es, although many more and equally interesting could have been presented.
\end{abstract}

Key words: Print, Monarchy; Immaculate Conception; Defense; Doctrine. 
El culto al misterio de la Inmaculada Concepción que vive un período de auge en la España del siglo XVII, hunde sus raíces en la Edad Media. El origen de este culto tuvo lugar en Oriente hacia el siglo VIII, como dijo Elías Tormo:

"No es la Iglesia latina y romana la que inventó esas sentencias absolutas con las que se apellida secularmente a la Virgen Madre Purísima, Madre castísima, Madre inviolata, Madre intemerata (...). La letanía griega inventó y reforzó, y sobreinventó y sobrecompletó los adjetivos con que se le dice purísima y se le dice inmaculada a la Madre de Dios: achratos, sin mancha; amamos, sin mancilla; y la toda santa, la toda inocente: panagia, panagra..."1.

De la misma opinión son Trens y Stratton; Cabello Morales también apunta su origen oriental, pero lo adelanta al siglo IV, basándose en un texto de San Efrén ${ }^{2}$. Este culto llegó a la Península a través de Sicilia y el Sur de Italia ${ }^{3}$, siendo la Corona de Aragón el primero de los reinos peninsulares en el que penetró el culto a la Inmaculada, debido a que estaba abierto al Mediterráneo y tenía fuertes contactos con Sicilia y el Sur de Italia ${ }^{4}$.

El papel de los monarcas tanto aragoneses como castellanos, como posteriormente de los Austrias, fue fundamental en la difusión del culto a la Inmaculada Concepción. En el caso de los monarcas aragoneses hay que destacar a Jaime I, que apoyó a San Pedro Nolasco para fundar la Orden de la Merced,- cuyo hábito es blanco en referencia a la pureza inmaculada de la Virgen ${ }^{5}$-, o a Juan I, - que en el año 1394 publicó su edicto a favor de la Inmaculada ${ }^{6}$. Como ya indicó Suzanne Stratton, esta devoción no tuvo su origen en el pueblo, sino que fue filtrándose de los teólogos franciscanos a los reyes y a la nobleza y, por último, al pueblo llano?

Sin embargo, los dos primeros reyes españoles de la dinastía de los Austrias no apoyaron directamente la doctrina, sino que dejaron su discusión en manos de los teólogos. Esta actitud estuvo indudablemente marcada por el problema de la Reforma, ya que quisieron evitar entrar en controversia sobre temas teológicos que llevaban discutiéndose varios siglos y que habían generado enconadas disputas entre los maculistas, dominicos, y los inmaculistas, franciscanos. Carlos $\mathrm{V}$ comprendió que un debate profundo sobre este misterio sólo haría ahondar las diferencias entre católicos y reformados ${ }^{8}$. Esta actitud del Emperador se ve reflejada perfectamente en la carta

1 TORMO, Elías., La Inmaculada y el arte español, Madrid, Fototipia de Hauser y Menet, 1915, p. 13.

2 TRENS, Manuel., María: iconografía de la Virgen en el arte español, Madrid, Plus Ultra, 1946, p. 165; STRATTON, Suzanne., La Inmaculada Concepción en el Arte Español, Madrid, F.U.E, 1988, p. 3; CABELLO MORALES, P. V., "La Inmaculada Concepción”, en Gratia Plena: La llena de Gracia, catálogo de la exposición (Córdoba, 2004), Córdoba, Publicaciones de la obra social y cultural Cajasur, 2004, p. 294.

3 TRENS, Manuel (1946), op. cit., 1946, p. 165.

4 STRATTON, Suzanne (1988), op. cit., 1988, p. 9.

5 Ibid.

6 ROS, Carlos, "La Concepción Inmaculada en la Historia", en las Actas del XV Simposio de Historia de la Iglesia en España y América, (Sevilla, 2004), Córdoba, Publicaciones de la Obra Social y Cultural de Cajasur, 2007.

7 STRATTON, Suzanne (1988), op. cit., p. 32.

8 Ibid., p. 33. 
que escribió el 13 de junio de 1546 desde Ratisbona, al cardenal jienense D. Pedro Pacheco, que encabezaba el grupo imperial en el Concilio de Trento, en la que manifiesta su desagrado por su modo de llevar la discusión del privilegio en las sesiones conciliares, que el cardenal planteó a raíz de la discusión sobre la doctrina del pecado original. Carlos $\mathrm{V}$ hizo hincapié en que era inútil entretenerse en una cuestión que no formaba parte de las controversias entre católicos y protestantes, por cuya causa había sido convocado el Concilio, y que con las interminables disputas no se conseguía otra cosa sino hacer más incierta la tesis favorable a la Virgen ${ }^{9}$.

En dicho Concilio se estuvo más cerca de negar la doctrina que de aprobarla a pesar de los intentos del cardenal Pacheco por lograr su aprobación. Finalmente, los padres conciliares optaron por una solución que, si bien no aprobaba el misterio, sí daba pie a su futura defensa.

A fines del siglo XVI e inicios del XVII en España se produce una campaña a favor del misterio inmaculista, que tuvo por epicentro Andalucía, concretamente Granada, Córdoba y Sevilla, y estuvo orquestada por el arzobispo don Pedro de Castro, que primero lo fue de Granada y posteriormente de Sevilla ${ }^{10}$. En esta campaña jugaron un papel muy destacado unas reliquias halladas en Granada a fines del siglo XVI, cuando era obispo de la ciudad don Pedro de Castro, como se narra en el libro Relación breve de las reliquias que se hallaron en la Ciudad de Granada en una Torre antiquísima y en las cavernas del Monte Illipulitano de Valparaíso, cerca de la ciudad, sacdo del proceso y averiguaciones que cerca de ello se hicieron (Granada, 1614). El papel de este prelado en dicha campaña ya lo puso de relieve Ortiz de Zúñiga ${ }^{11}$. Esta campaña se plasmó en una serie de fiestas, procesiones y ceremonias que se organizaron a favor del misterio, tanto en Sevilla como en otras ciudades españolas, aunque del caso sevillano conservamos una fuente excepcional de las fiestas que se organizaron en el año de 1615; es ésta el cuadro de Juan de Roelas conservado en Valladolid, y que hizo para lograr el apoyo de Felipe III en la defensa del dogma ${ }^{12}$.

La actitud de los Austrias menores respecto al culto a la Inmaculada Concepción fue radicalmente distinta a la de sus predecesores. La Monarquía Hispánica, que desde Felipe II se había convertido en la gran defensora de la catolicidad, tenía por estandarte la Eucaristía pero, desde estos momentos, junto a ésta va a tener a la Inmaculada Concepción. Para los monarcas, la proclamación como dogma de la doctrina, se va a convertir en la piedra angular de su política exterior en Roma, tratando de demostrar

9 OLAZARÁN, Jesús, "El dogma de la Inmaculada Concepción en el Concilio de Trento", en Estudios Eclesiásticos, nº76-77, 1946, p. 144.

10 Sobre la devoción a la Inmaculada en Sevilla resultan muy interesantes los artículos de ROS, Carlos, op. cit., pp. 26-33; y el de MARTÍN DE LA HOZ, José Carlos, "La Inmaculada y Sevilla: Siglo XVII", pp. 159166, en las Actas del XV Simposio de Historia de la Iglesia en España y América, (Sevilla, 2004), Córdoba, Publicaciones de la Obra Social y Cultural de Cajasur, 2007.

11 ORTIZ DE ZÚÑ̃IGA, Diego, Annales eclesiásticos y seculares de la muy noble y muy leal ciudad de Sevilla, metrópoli de Andalucía, T. IV, Madrid, Imprenta Real, 1796, pp. 234-235.

12 STRATTON, Suzanne (1988), op. cit., p. 62; PORTÚS PÉREZ, Javier, "Religión, poesía e imagen en el Siglo de Oro", en Verso e imagen. Del Barroco al Siglo de las Luces, catálogo de exposición (Madrid, 1993) Madrid, Calcografía Nacional: Dirección General de Patrimonio Cultural, Comunidad de Madrid, 1993, p. 317. 
cómo conservaban allí su peso político ${ }^{13}$. Para ello, Felipe III, Felipe IV y Carlos II, van a convocar una serie de Reales Juntas, en las que se decidió el envío de embajadores extraordinarios a Roma con el fin de lograr la declaración del misterio como dogma de fe. En la primera de ellas, convocada por Felipe III en 1616, jugó un papel muy importante la presión ejercida desde Sevilla ${ }^{14}$, y por otra parte, la influencia de su tía, sor Margarita de la Cruz, desde el convento madrileño de las Descalzas Reales ${ }^{15}$.

Esta actitud de los monarcas va a tener su plasmación en el arte y, muy especialmente, en las estampas,- como ya señaló Suzanne Stratton al referirse a una estampa de Paulus Pontius siguiendo un esbozo al óleo de Rubens, fechado entre 1631 y 1632, que presenta a Felipe IV y a sus antepasados Habsburgo defendiendo a la Inmaculada. En el centro de la estampa se dispone San Francisco, como Seraphicus Atlas, sosteniendo tres esferas sobre sus hombros, sobre las que se alza la Inmaculada. A la izquierda vemos a cuatro monjes franciscanos, entre los que se identifica a Duns Scoto, considerado uno de los más fervientes defensores del misterio, que empuja a la herejía a la boca del infierno. A la derecha, acompañados de unos franciscanos, están Felipe IV, el Cardenal Infante, el príncipe Baltasar Carlos y Don Carlos. La presencia del príncipe Baltasar Carlos hace referencia a la continuidad dinástica. En la parte superior, en medio de un rompimiento de gloria y llevados en un carro, están sus antepasados: Carlos V, Felipe II y Felipe III ${ }^{16}$. En ella no sólo se hace hincapié en la defensa que del misterio hizo la dinastía de los Habsburgo, sino también cómo la Orden Franciscana fue su adalid, como veremos en otras estampas.

En este artículo pretendo centrarme en una serie de estampas en las que se capta esa idea de la Monarquía Hispánica como defensora del misterio inmaculista. Podríamos considerarlas unos magníficos ejemplos del arte al servicio del poder, en este caso concreto del poder político. Además responden a un afán marcadamente propagandístico, ya que se incide en la idea de cómo la monarquía, personificada en la figura del rey, defiende una de las devociones con mayor arraigo en el pueblo. Todas ellas se fechan en las décadas de 1640 y 1650, cuando reinaba Felipe IV, al que se dedican todos los libros.

Estas estampas ilustran una serie de libros dedicados al misterio inmaculista de mediados del siglo XVII. Hay que tener presente que el libro fue el principal destinatario de las estampas producidas a lo largo de esta centuria ${ }^{17} \mathrm{y}$ en ellos podemos apreciar algunas de las características del libro ilustrado español de este siglo. En estos momentos se produce una contradicción entre una objetiva decadencia del libro,- sobre todo a nivel material y de diseño debido a la crisis económica imperante

13 VV.AA., Historia de la Iglesia en España, T. IV., Madrid, La Editorial Católica, 1979, p. 458; STRATTON, Suzanne (1988), op. cit., p. 80; CABELLO MORALES, P. V., op. cit., p. 296.

14 STRATTON, Suzanne (1988), op. cit., p. 59.

15 GONZÁLEZ GÓMEZ, Juan Miguel, "Reflejos de la perfecta hermosura. Escultura, iconografía y devoción inmaculista en Sevilla", en Inmaculada. 150 años de la proclamación del dogma, catálogo de exposición (Córdoba, 2004), Córdoba, Publicaciones de la Obra Social y Cultural Cajasur, 2004, p. 93.

16 STRATTON, Suzanne (1988), op. cit.., p. 59.

17 CARRETE PARRONDO, Juan., "Grabado y literatura en la España barroca”, en Verso e imagen. Del Barroco al Siglo de las Luces, catálogo de exposición (Madrid, 1993), Madrid, Calcografía Nacional: Dirección General de Patrimonio Cultural, Comunidad de Madrid, 1993, p. 282. 
en la España del siglo XVII, y por la necesidad de abaratar los costes para llegar a un público más amplio-, y la obsesión de los autores, editores e impresores por incluir en los mismos calcografías que aumentaban enormemente los costes ${ }^{18}$. Esto provocó que se redujera el número de estampas en los libros generalmente a la portada o, si acaso, al retrato del autor o de la persona a la que se dedicaba el libro. Sin embargo, hay excepciones realmente sobresalientes como la Psalmodia Eucharística de fray Melchor Prieto o las Fiestas de la Iglesia santa metropolitana y patriarcal de Sevilla, al nuevo culto del señor el Rey San Fernando III de Castilla y de León de Fernando de la Torre Farfán.

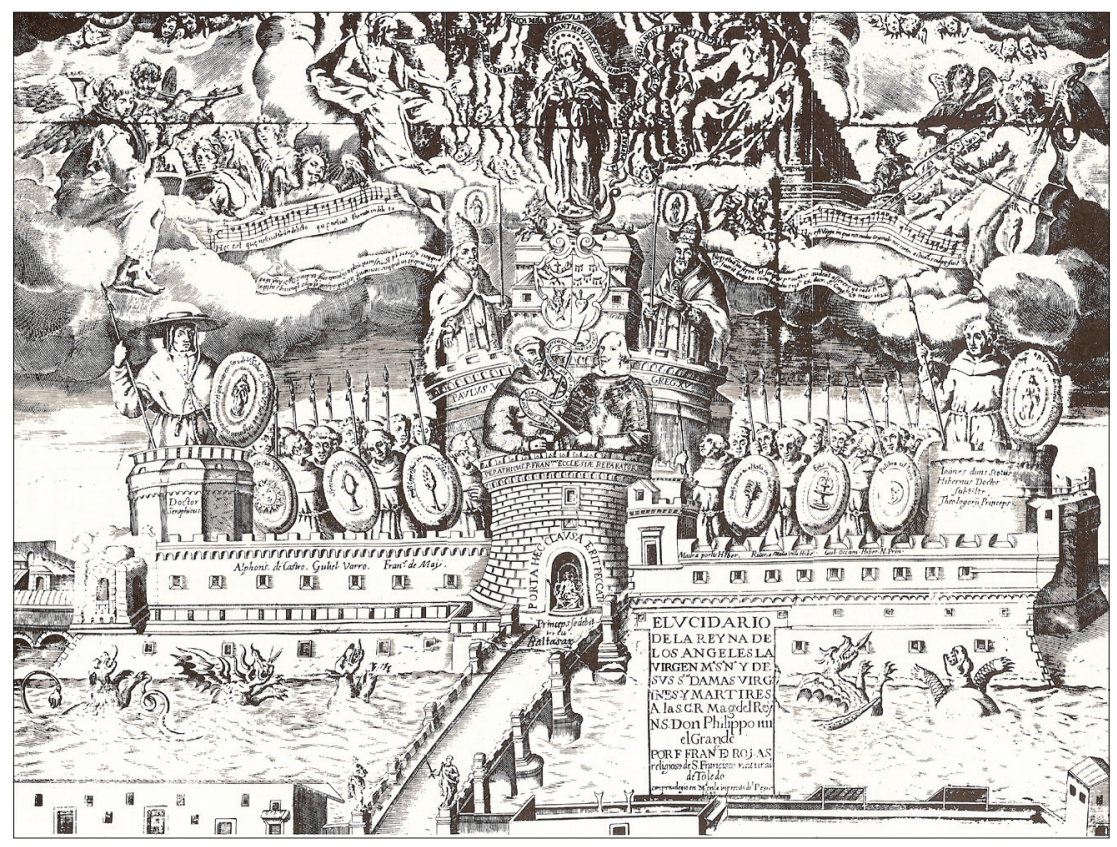

Fig. 1. Eluzidario de las Reyna de los Ángeles, Anónimo, 1649, Entalladura, 38 x 48 cm., [tomado de GARCÍA VEGA, Blanca, El grabado del libro español. Siglos XV, XVI y XVII, T. I, Valladolid, 1984, fig. 937].

La primera de las estampas a las que nos vamos a referir es la que ilustra la obra del franciscano fray Francisco de Rojas, Eluzidario de la Reyna de los Ángeles, editado en Madrid en 1643 (Fig. 1). Este libro fue publicado el mismo año en que Felipe IV convocó la Real Junta con el fin de lograr la definición del dogma de la Inmaculada, aunque dicha Junta le aconsejó que era preferible que presionara al Papa Urbano VIII para que estableciese una fiesta a favor del patronazgo de la Purísima en España

18 Ibíd.; CARRETE PARRONDO, Juan, "El grabado y la estampa barroca”, en Summa Artis: Historia General del Arte, Vol. XXXI, El grabado en España del siglo XV al XVIII, Pijoán, José (Dir.), Madrid, Espasa-Calpe, 1996, p. 247. 
porque era improbable que el Papa definiese la doctrina como dogma ${ }^{19}$. Esta estampa hace hincapié en la defensa que hicieron del misterio algunas órdenes religiosas como los franciscanos, a la que pertenecía el autor de este libro, los monarcas hispanos y algunos Papas, como Paulo V y Gregorio XV, que con sus decretales favorecieron la doctrina. Además se puede considerar una imagen de la Iglesia militante que se defiende de los ataques de los demonios. Esta imagen de la Iglesia militante cobró fuerza tras el Concilio tridentino y durante gran parte del siglo XVII, porque la Iglesia tuvo que enfrentarse a los reformados y recuperar el territorio perdido ante éstos en la anterior centuria. Hay que tener presente que esta estampa se abrió cuando aún no había terminado la Guerra de los Treinta Años, que se puede considerar la última y mayor guerra de religión entre los católicos y los reformados.

Compositivamente se estructura en dos partes: la terrenal y la celestial, dominadas por la figura de la Purísima, que sirve de nexo entre ambas. El cartel con el título, el autor y la dedicatoria ocupa un lugar secundario en la parte inferior derecha. El libro, como vamos a ver en los otros ejemplos aquí tratados, está dedicado a Felipe IV.

En la parte terrenal llama poderosamente la atención la gran fortaleza, que recuerda a Castel Sant'Angelo, que vendría a ser una imagen de la propia Iglesia militante y quizás, al mismo tiempo, sería una forma de presionar al Papado para que definiese el dogma. Está rodeada de un foso con agua del que emergen varios seres monstruosos que la asedian sin resultado. Esta fortaleza está unida con la tierra por un puente que en su inicio tiene unas estatuas de San Pedro y San Pablo sobre unos pedestales. El alcázar está defendido por unos poderosos baluartes en sus extremos en los que se encuentran Santo Tomás de Aquino en el de la izquierda y Duns Scoto en el de la derecha. La presencia del dominico, al que se denomina Doctor Seraphicus, resulta, cuanto menos, peculiar porque fue defensor de la opinión contraria al misterio aunque algunos han considerado que en uno de sus últimos escritos sobre el Magnificat daba pie a la defensa del misterio ${ }^{20}$. Va vestido de cardenal y armado con una lanza y un escudo en el que se ve una imagen de la Inmaculada rodeada de una leyenda que dice: "Solus in filius V. fuit ab originali culpa inmunis et ipsa mater eius Ser. de $V$ ". En el otro torreón vemos a Duns Scoto, al que acompaña esta inscripción: "Ioannes duns Scotus Hibernus Doctor Subtites Theolegorum Princeps". La presencia de Scoto se explica porque se le consideraba uno de los más firmes defensores del misterio, y como veíamos en la estampa de Paulus Pontius va a ser habitual hallarlo en las estampas de tema inmaculista. Va ataviado con su hábito franciscano y armado con una lanza y un escudo en el que también vemos a la Inmaculada rodeada de una inscripción latina alusiva al misterio, que reza: "B.V. mater dei numqua fuit inimica actualiter none pecati Originalis". En los muros de la fortaleza se ve una multitud de frailes franciscanos provistos de lanzas, que son la imagen de la Iglesia militante que surgió del Concilio de Trento y que se nos muestra como defensora del misterio. Entre estos monjes podemos identificar a los que se encuentran en primera fila, porque en el muro hay unas inscripciones con sus nombres, en el lado izquierdo están: Alphons de Castro, Guliel Varro y Francesco de Maii; en el derecho: Maur. a portu

19 STRATTON, Suzanne (1988), op. cit., p. 80; GONZÁLEZ GÓMEZ, Juan Miguel (2004), op. cit., p. 95.

20 PEDRAZA, Pilar, Barroco efimero en Valencia, Valencia, Ayuntamiento de Valencia, 1982, p. 39. 
Hiber, Ricar a Media Villa Hibe, y Gul. Occam Hiber N. Prin. En ellos podemos observar una gran variedad de actitudes, algunos inclinan su cabeza, dirigiendo su mirada hacía el foso, mientras que otros miran al cielo, a la Inmaculada Concepción Cada uno de ellos porta un escudo ornado con uno de los emblemas de las Letanías con sus respectivas inscripciones, y que de izquierda a derecha son: el sol (Electa ut sol), el espejo sin mancha (Speculum sine macula), el ciprés (quasi cippressum in Monte Sion), la palmera (Quasi palma ocultata in cades), la fuente de agua viva (Fons vivus) y la luna (Pulchra ut luna).

A este castillo se accede por un arco en cuyo trasdós leemos: "Porta haec clausa erit peccato", que hace referencia a la Puerta del Paraíso que fue cerrada a causa del pecado de los primeros padres que, según el misterio inmaculista, no afectó a la Virgen. Custodiándola hay una figura sedente, a la que identificamos gracias a la leyenda que hay a sus pies: "Princeps sedebit in eu Baltasar", es decir, es el príncipe Baltasar Carlos, con lo que habría que considerarla la primera alusión a la Monarquía Hispánica. En la almena central de la fortaleza a un lado está San Francisco y al otro Felipe IV. En el friso que rodea dicha almena se lee esta inscripción: "Seraphicus P. Francus Ecclesiae reparator", que hace referencia a San Francisco como el reparador de la Iglesia. El santo muestra el estigma de una de sus manos, en la que porta una espada, y tiene una filacteria con una leyenda, que reza: "Accipe sanctum gladium manus a Deo sit quo deycies adversarius, 2 mach. Cap. 15", que haría referencia a la espada que Dios dio a Macabeo para expulsar a los enemigos de Israel, y que en manos del santo serviría para expulsar a los enemigos de la Iglesia, los herejes representados en el foso como los dragones. El rey Felipe IV se encuentra al otro lado del torreón con armadura, como campeón de la Inmaculada y defensor de la Iglesia, como expresa en la dedicatoria del libro fray Francisco de Rojas: "No de otra suerte a V. Sacra Magestad le tiene Dios en su Iglesia plantado, para que las tempestades que contra la Fe levantan los Hereges, ampare y defienda a la Iglesia con sus exercitos..." ${ }^{21}$; en una de sus manos lleva un bastón de mando, y con la otra agarra la espada que lleva San Francisco. En la torre del homenaje está el escudo de la Orden franciscana y sobre ésta se encuentra la figura de la Purísima. A los lados de esta torre están los Papas Paulo V y Gregorio XV,- a izquierda y derecha respectivamente-, a los que identificamos porque sus nombres están inscritos en el friso del torreón. Van ataviados con unas albas con estolas, y sobre ellas llevan unas magníficas capas pluviales; sobre sus cabezas tienen unas tiaras con la triple corona. Cada uno de ellos sostiene con una de sus manos un estandarte con la figura de la Inmaculada. Les acompañan unas grandes filacterias en las que se recogen unos fragmentos de sus decretos en los que defendían el misterio. De esta forma se trata de presionar al Papa Urbano VIII para que defienda el misterio, poniéndole como ejemplo a estos dos pontífices.

La parte celestial está presidida por la figura de la Inmaculada, que presenta los atributos de la Mujer Apocalíptica, la Tota Pulchra y la Nueva Eva. A sus pies se encuentra la luna y bajo ésta el dragón, símbolo del pecado y de la propia herejía que es vencida por la Virgen. De su boca sale una filacteria con una leyenda latina que

21 ROJAS, Francisco de, Eluzidario de las Grandezas de la Virgen María, Madrid,1643, p. 2 
hace referencia a la vida eterna. Por encima de ella está la Trinidad, con la paloma del Espíritu Santo sobre su cabeza, de cuyo pico salen los versículos del Cantar de los Cantares que dan nombre a la Tota Pulchra: "Tota Pulchra est amica mea, et macula non". Dios Padre y Dios Hijo están a los lados, con unos cetros flordelisados y unas filacterias con textos alusivos al misterio. La filacteria que sale de la boca de Cristo tiene una inscripción latina prácticamente ilegible, que alude al dragón del pecado. La que surge de la boca de Dios Padre, presenta un texto del libro de la Sabiduría, que

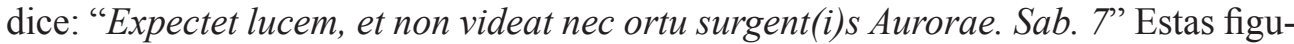
ras están sentadas en unas nubes en medio de un rompimiento de gloria. A los lados vemos los coros celestiales, constituidos por ángeles mancebos que tañen instrumentos, y delante de ellos hay unas partituras con la letra del salmo que están entonando, que nuevamente aludiría a como el pecado original no afectó a la Virgen. Blanca García ha destacado la enorme soltura con la que se hicieron los ángeles del coro, frente a la mayor rigidez de las figuras de la parte terrenal ${ }^{22}$, lo que lleva a pensar que la parte celestial fuera realizada por un maestro conocedor de la técnica, mientras que la terrenal fuera obra del taller.

En el año 1647 un hecho va a marcar profundamente el desarrollo del misterio y su defensa por parte del monarca español, Felipe IV. Éste fue la aprobación por parte de la Inquisición General en Roma de un decreto en el que se prohibía aplicar el término Inmaculada al hablar de la Concepción de la Virgen y que fue confirmado por el Papa Urbano VIII, cuyas relaciones con Felipe IV fueron más bien tensas, y que en varias ocasiones se mostró partidario de las tesis maculistas ${ }^{23}$. A este hecho hace referencia la dedicatoria a Felipe IV del libro Pro titulo Inmaculatae Concepta, con estas palabras: “(...) quo anno 1647 mẽse Ianurio universos in admirationem rapuisti, nam cū Regnorum Comitia te consulerent super decreto (ut putabatur) Sanctue Romanae Inquisitionis prohibent tribui Conceptioni titulum Inmaculatae (...)" ${ }^{24}$. Este hecho va a provocar que en España, desde finales de la década de 1640 y durante la siguiente década, haya una enorme actividad editorial de libros dedicados al misterio, con sus respectivas estampas en las portadas. Aquí vamos a estudiar algunos ejemplos muy significativos.

La siguiente estampa que vamos a estudiar es la que ilustra la anteportada del libro de Gaspar de la Fuente Armamentarium seraphicum et regestum universale tuendo titulo Inmaculatae Conceptionis, publicado en Madrid en $1649^{25}$ (Fig. 2). Esta estampa fue abierta por Herman Panneels, uno de los muchos grabadores flamencos que se asentaron en España desde finales del siglo XVI. Tiene una estructura arquitectónica a modo de torreón o baluarte. En la parte inferior, a los lados se ven parejas de querubes que parecen conversar; dos de ellos sostienen con sus manos la tela de la parte central, en donde se dispone el título y la firma de Panneels. En el centro de este

22 GARCÍA VEGA, Blanca, El grabado del libro español. Siglos XV, XVI y XVII, T. I, Valladolid, Institución Cultural Simancas: Diputación Provincial de Valladolid, 1984, p. 143.

23 VV.AA. (1979), op. cit., p. 459.

24 CALDERÓN, Antonio, Pro titulo Inmaculatae Concepta, Madrid, por Diego Díaz de la Carrera, 1650, sin paginar.

25 Biblioteca Nacional de España, 3/12471. 


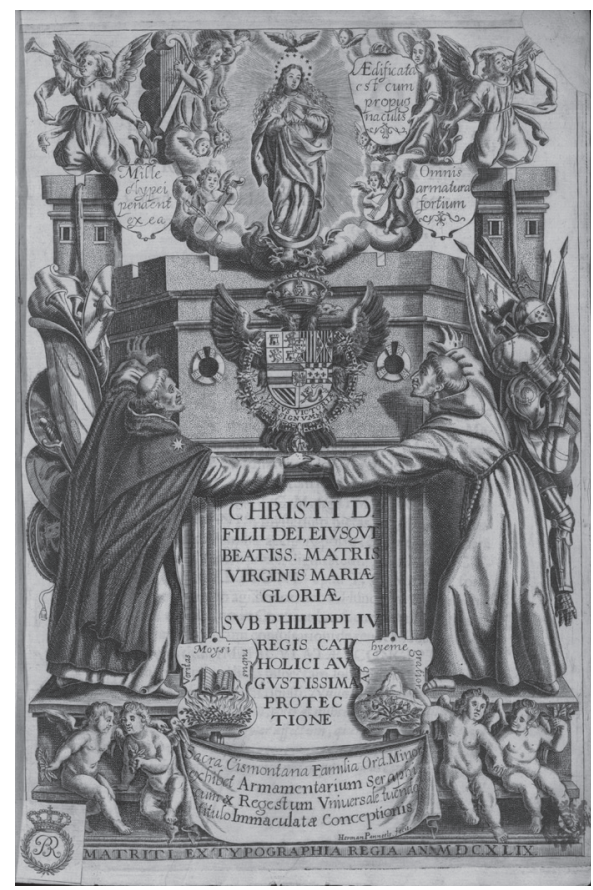

Fig. 2. Armamentarium seraphicum et regestum universale tuendo titulo Inmaculatae Conceptionis, Herman Panneels, 1649, Talla dulce, 19 x 28,3 cm., Madrid (España), Biblioteca Nacional de España, 3/53883.

torreón poligonal se abre un vano en el que leemos la dedicatoria a Felipe IV: "Christi D. Fil. II Dei eiusque Beatiss. Matris Virginis Mariae Gloriae. Sub Philippi IV Regis Catholici avgustissima protectione", con lo que se hace referencia al monarca como defensor de la doctrina. A los lados, de pie sobre el basamento del baluarte vemos las figuras de Santo Domingo de Guzmán, ataviado con el hábito dominico y con una estrella sobre su hombro derecho, y San Francisco de Asís con el hábito franciscano. Ambos santos elevan sus miradas hacia la figura de la Inmaculada que está sobre el baluarte y unen sus manos en la parte central, simbolizando la unión de los dominicos y franciscanos en la defensa del misterio ${ }^{26}$. Junto a estos santos cuelgan unas armas, escudos y corazas que hacen referencia al título del libro, que sería una forma de simbolizar la defensa del misterio. A la que se suma la Monarquía Hispánica representada por el escudo de Felipe IV con el águila bicéfala, la cadena de la que cuelga el Toisón de Oro, al que acompaña una leyenda que dice: "Vellus Victoria Signum",

\footnotetext{
26 CACHEDA BARREIRO, Rosa Margarita, "Dogma, ideología y devoción: La Inmaculada Concepción a través de las estampas del siglo XVII", en las Actas del simposium: La Inmaculada Concepción en España: religiosidad, historia y arte (San Lorenzo de El Escorial, 2005), Ediciones Escurialenses: Real Centro Universitaria de El Escorial-María Cristina, Vol. II, p. 852; CACHEDA BARREIRO, Rosa Margarita, La portada del libro en la España de los Austrias Menores. Un estudio iconográfico, 2006, p. 406.
} 
y una corona. Sobre este torreón se encuentra la figura de la Inmaculada, que sigue la iconografía habitual de mediados del siglo XVII. Para Cacheda Barreiro, Herman Panneels pudo inspirarse en algunas pinturas por el movimiento de las manos y por la expresividad del rostro ${ }^{27}$. La Inmaculada tiene sobre su cabeza la paloma del Espíritu Santo y a los lados, unos ángeles que tañen diversos instrumentos musicales salvo uno que sostiene una tarja con esta inscripción: "Aedificata est cum propugnaculis" (La torre es inexpugnable). En los extremos hay dos ángeles mancebos que tocan unas largas trompetas, mientras sostienen unos escudos con unas inscripciones latinas, en el de la izquierda leemos: "Mille clypei pendent ex ea" (De la cual penden mil escudos), y en el de la derecha: "Omnis armatura fortium" (Fuerte en toda armadura).

La idea de la torre tiene una fuerte vinculación con la Inmaculada Concepción, puesto que dos de los emblemas de las Letanías marianas hacen referencia a la torre, que son la Torre de David y la Torre de Marfil. Al mismo tiempo hace referencia a la defensa del misterio, como parecen señalar las inscripciones a las que aludimos un poco más arriba.

A los pies de los santos hay unas tarjas con unos emblemas que completan el significado de esta estampa. En la de la izquierda vemos la zarza ardiendo sobre la que hay un libro con esta leyenda: "Veritas Moysi rubus" (Verdad Moisés Espino), y en la de la derecha una mata de rosas y un monte al fondo con esta inscripción: "Ab hyeme gratior" (Más agradable desde el invierno). La zarza ardiendo se toma de un pasaje del Éxodo (Ex. 3, 1-4), sería símbolo del fuego espiritual que no quema y María pudo ser Madre siendo Virgen, como se expresa en uno de los jeroglíficos de Nicolás de la Iglesia con el mote: "Rubis incombustus" (La zarza que no se quema) ${ }^{28}$. A esta misma idea responde uno de los emblemas del Imago Primo Saeculi (Amberes, 1640), con el lema: "Rubus ardens incombustus" (Zarza ardiente que no se consume), con la figura de Moisés delante de la zarza en referencia a la íntegra castidad, tal y como expresa el título de la empresa "Castitas integra" ${ }^{29}$. El libro abierto representa las tablas de la ley, que Dios entregó a Moisés en el Monte Horeb, como narra el libro del Éxodo (Ex. $24,12)$. La planta de rosas es uno de los emblemas tradicionales de la Inmaculada, que se toma de un versículo del Eclesiástico, que dice: “...como plantel de rosas de Jericó" (Si. 24, 14).

También fue Herman Panneels el encargado de abrir la anteportada del libro de Antonio Calderón Pro titulo Inmaculatae Conceptionis, editado por Diego Díaz de la Carrera en Madrid en $1650^{30}$ (Fig. 3). Al igual que los anteriores ejemplos está dedicado a Felipe IV, al que en la dedicatoria del libro se recuerda la defensa que habían hecho siempre los Austrias de la doctrina inmaculista ${ }^{31}$. Esta portada no presenta la característica estructura arquitectónica de las portadas de los libros españoles del siglo XVII. En la parte inferior hay una gran cartela, que en el centro tiene el escudo

27 Ibid, p. 410.

28 DE LA IGLESIA, Nicolás, Flores de Miraflores Hieroglificos sagrados, verdades figuradas, sombras verdaderas del misterio de la Inmaculada concepción de la Virgen, y madre de Dios María señora nuestra, Burgos. 1659, p. 54; citado por CACHEDA BARREIRO, Rosa Margarita (2006), op. cit.., p. 408.

29 Imago Primo Saeculi; citada por CACHEDA BARREIRO, Rosa Margarita (2006), op. cit., p. 408.

30 Biblioteca Nacional de España, 3/53883.

31 CALDERÓN, Antonio, op. cit., 1650, sin paginar. 


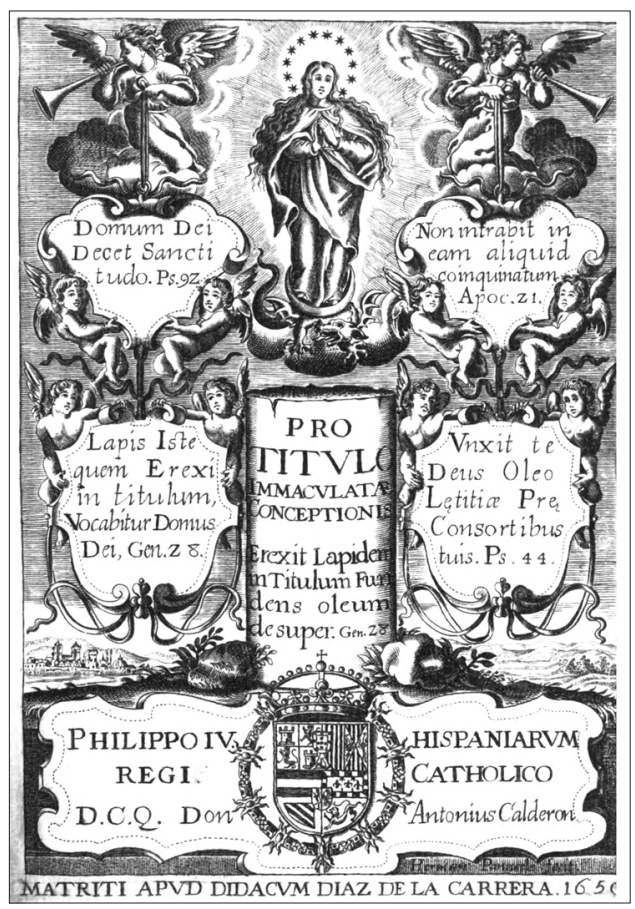

Fig. 3. Pro titulo Inmaculatae Conceptionis, Herman Panneels, 1650, Talla dulce, 18,0 x 13,0 cm., Madrid (España), Biblioteca Nacional de España, 3/1247.

de Felipe IV, flanqueado por una inscripción, que dice: "PHILIPPO IV - HISPANO$R U M-R E G I-C A T H O L I C O$ ", y debajo está el nombre del autor del libro. En el centro de la estampa hay una columna partida por la mitad del fuste, que marca el eje de simetría. En ella vemos el título y debajo hay una inscripción con un pasaje del Génesis: "Erexit Lapidem in Titulum Fundens óleum de super Gen. 28" (...la erigió como estela y derramó aceite sobre ella). Esta columna partida sirve de pedestal a la figura de la Inmaculada Concepción, que se encuentra en la parte superior en medio de un rompimiento de gloria. Se la representa como una muchacha joven, en actitud de recogimiento orante, está rodeada de una aureola de luz con su cabeza con nimbo de estrellas, cubierta de una larga melena que le cae sobre los hombros. Bajo sus pies está la luna y bajo ésta se encuentra el dragón. Esta Inmaculada presenta una clara semejanza con la figura que veíamos en la estampa anterior. Esta columna con la Inmaculada estaría en relación con la que se había erigido en Viena, a lo que se alude en la dedicatoria del libro, con estas palabras: "Inmaculatae Virginis efigiem egregie columnae insistentem (opus ingentibus sumptibus paratum) erexit Vienae in faro ante Domum professam Societatis Iesu..." ${ }^{32}$.

32 Ibid. 
En la parte superior, a los lados y arrodillados sobre unas nubes, hay unos ángeles mancebos que tañen unas largas trompetas, girándose uno a la derecha y el otro a la izquierda. Cada uno de ellos sostiene con una de sus manos, unas cintas de las que cuelgan dos medallones de cueros recortados que son a su vez sostenidos por parejas de querubines. En estos medallones se recogen diversos versículos bíblicos que hacen referencia al misterio inmaculista. En el primero de la izquierda se lee un versículo del Salmo 92: "Domum Dei decet Sancti tudo. Ps. 92" (...la santidad está sentada en la casa de Dios), que hace alusión a la Casa de Dios, que se podría identificar con la Virgen, porque por el misterio de la Encarnación Cristo fue a morar en su vientre. En el segundo medallón se recoge otro versículo del capítulo 28 del Génesis, que dice: "Lapis iste quem Exeri in titulum Viocabitur Domus Dei. Gen 28" (esta piedra que he erigido como estela será llamada Casa de Dios), que hace también referencia a la Casa de Dios. En el primer medallón de la derecha se recoge un versículo del capítulo 21 del Apocalipsis: "Non intrabit in eam aliquid coinquinatum. Apoc. 21" (No entrará en ella nada corrompido), que se toma de la visión de la Jerusalén celeste y hace hincapié en la idea de que nada manchado entrará en ella, con lo que simbolizaría a la Inmaculada Concepción que no se vio manchada por el pecado original. La identificación de la Inmaculada Concepción con la Jerusalén Celestial es bastante habitual en esta época, como podemos ver en las portadas de diversas ediciones del libro de sor María de Jesús de Agreda Mística Ciudad de Dios y milagro de su omnipotencia $^{33}$. El segundo medallón de la derecha contiene un versículo del Salmo 44, que dice: "Vnxit te Deus oleo Laetitiae Prei Consortibus tuis. Ps. 44" (Dios te ha ungido con óleo de alegría delante de tus compañeros), que haría referencia a cómo la Virgen fue elegida por Dios antes de todos los tiempos como la Madre de su Hijo $\mathrm{y}$, por tanto, libre del pecado original.

Tenemos que destacar la portada del libro Vox Haec nunciat omnes. Maria Inmaculata Concepta, escrito por el jesuita Juan Antonio Velázquez y publicado en Madrid en $1653^{34}$ (Fig. 4). Del autor del libro hay que señalar que ocupó un cargo de importancia dentro de la Compañía de Jesús a mediados de dicha centuria, ya que fue padre provincial de Castilla y profesor del Colegio de Jesuitas de Salamanca, que era uno de los más importantes de la Península. Este libro viene a demostrar el papel preponderante de la Compañía de Jesús en la defensa de la doctrina inmaculista. Esta estampa, abierta por el sacerdote y grabador Marcos Orozco, se tiene que considerar como una de sus primeras obras y sigue el gusto imperante en la Corte matritense por las portadas arquitectónicas aunque no tiene la estructura a modo de retablo, como era habitual. En ella se trata de mostrar a la Compañía de Jesús como una de las defensoras del misterio y, al igual que en los ejemplos anteriores, se alude a la defensa que de la misma hizo el monarca español, Felipe IV.

33 Podríamos destacar algunas de las ediciones de dicha obra de Sor María de Jesús de Agreda, como la realizada en Madrid en 1670, cuya portada se debe a Pedro de Villafranca (Biblioteca Nacional de España, 3/52739), o la de Valencia de 1696 (Universidad Complutense de Madrid, Biblioteca Histórica Marqués de Valdecilla, BH FLL 3581), y la de Amberes de 1698 (Universidad Complutense de Madrid, Biblioteca Histórica Marqués de Valdecilla, BH DER 9658).

34 Universidad Complutense de Madrid, Biblioteca Histórica Marqués de Valdecilla, BH DER 5146. 


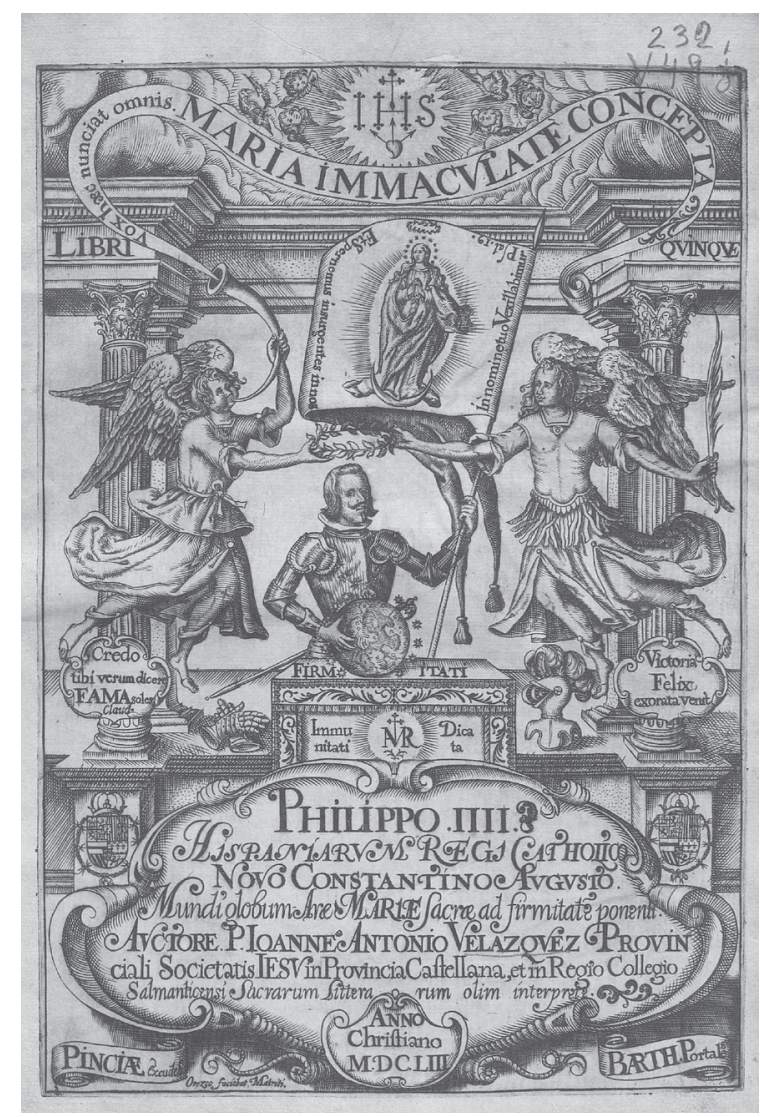

Fig. 4. Vox Haec nunciat omnes. Maria Inmaculata Concepta, Marcos Orozco, 1653, Talla dulce, 16,9 x 25,0 cm., Madrid (España), Universidad Complutense de Madrid, Biblioteca Histórica Marqués de Valdecilla, BH DER 5146.

En la parte inferior, cubriendo parte del basamento de la estructura arquitectónica, hay un gran medallón de cueros recortados, de marcado gusto barroco, en el que aparece el nombre del autor y la dedicatoria a Felipe IV, al que se denomina "Novo Constantino Augusto", porque se equipara al monarca hispano con Constantino, primer emperador cristiano. En un pequeño medallón, que hay debajo de éste siguiendo el eje vertical, se recoge la fecha de impresión (Anno Christiano 1653). Debajo del gran medallón vemos la firma de Marcos Orozco (Orozco faciebat. Matriti). En los ángulos podemos observar unas filacterias en las que se recogen unas inscripciones latinas, que dicen: "PINCIEE exeudeb", y "BARTH. Portales", a izquierda y derecha respectivamente

Del basamento de la estructura arquitectónica vemos exclusivamente los pilarones de los extremos, en unos escudos de Felipe IV. Sobre el alto basamento se levanta el cuerpo principal a modo de pórtico, sostenido por columnas. En la parte central 
de este pórtico, detrás de un pedestal, está Felipe IV. En la parte frontal del pedestal vemos en el centro las iniciales de la Virgen, y a los lados leemos las palabras latinas: "Immunitati" y "Dicata", que hacen referencia a la Virgen. El monarca aparece representado de medio cuerpo, vestido con una coraza y de su cuello cuelga una cadena con el Toisón de Oro. A los lados del pedestal se ven sus guanteletes, el casco con un magnífico penacho de plumas, y el cinturón del que cuelga una espada. Apoya su mano derecha en el orbe rodeado de estrellas, que descansa en el pedestal y le acompaña la palabra "FIRM-ITATT", que harían referencia a los dominios de la Monarquía y a su fuerza. En la izquierda lleva una magnífica banderola que ocupa el centro de la composición, en la que se representa a la Inmaculada siguiendo la iconografía definitiva de la misma que se había impuesto desde el primer tercio de esta centuria, con la luna bajo sus pies y la corona de estrellas y rodeada de una inscripción tomada del Salmo 19, que dice: "Et spernemus insurgents in nos - In nomine tuo Vexillabimur. Psal 19", que hace referencia al monarca como el abanderado de la Inmaculada. Este retrato de Felipe IV recuerda indudablemente a los velazqueños y sigue el modelo de los de Pedro de Villafranca, que desde 1654 pasó a ser el grabador de cámara del rey ${ }^{35}$, debido a que Marcos Orozco tuvo una estrecha vinculación con el grabador manchego. A los lados están las columnas del pórtico, delante de las cuales hay unos ángeles mancebos, que están coronando con el laurel a Felipe IV, como se hacía con los emperadores de la Antigüedad. El ángel mancebo de la izquierda va vestido con una túnica, cuya parte inferior se agita por el viento, eleva su cabeza al cielo, y tañe una trompeta que sostiene con una mano y de la que surge una larga filacteria en la que leemos el título del libro. El otro va vestido con una túnica y una pechera, con una de sus manos agarra una palma de la victoria. A los pies de estos ángeles mancebos hay unos medallones con inscripciones, en el de la izquierda leemos: "Credo tibi verum dicera FAMA sales Claudo", y en el de la derecha: "Victoria Felix exorata venit", que insiste en la idea de la fama, que logrará el monarca por su defensa del misterio. Remata la estructura arquitectónica en un entablamento, en cuyo friso en los extremos leemos: "LIBRI-QUINQUE". En la parte superior hay un rompimiento de gloria, presidido por las iniciales IHS y debajo un corazón atravesado por tres clavos, que es uno de los emblemas de la Compañía de Jesús, rodeados de una aureola de rayos y de bandas de nubes entre las que se observan cabezas de querubines.

Estas estampas nos sirven para comprender el importante papel que jugó la Monarquía Hispánica, y más concretamente Felipe IV, en la defensa del misterio de la Inmaculada Concepción. Tuvieron un importante papel propagandístico de la propia Monarquía, pero ciertamente limitado, porque sólo las élites socio-culturales podían acceder a este tipo de libros, ya que la sociedad española del siglo XVII era mayoritariamente analfabeta. Además presentan elementos simbólicos muy complejos, comprensibles sólo para personas con una formación a nivel teológico muy completa. Estas estampas, en definitiva, no son estampas populares, sino estampas cultas, y por lo tanto con una difusión limitada.

35 AINAUD, Juan., "Grabado", en Miniatura y grabado, Ars Hispaniae, Vol. 18, Madrid, Plus Ultra 1962, p. 297; BARRIO MOYA, José Luis, "Pedro de Villafranca. Pintor y grabador manchego del siglo XVII”, Cuadernos de Estudios Manchegos, nº 13, 1982, p. 121. 